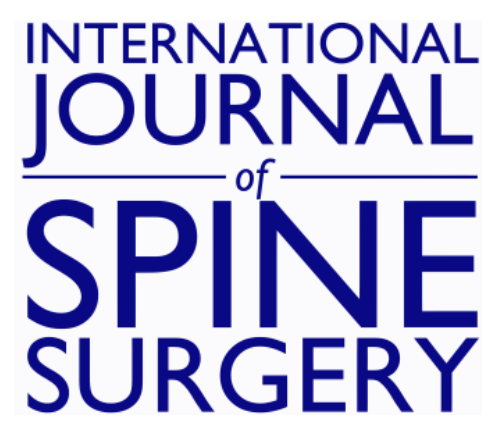

\title{
Single and Multilevel Lumbar Total Disc Replacement Adjacent to L5-S1 ALIF (Lumbar Hybrid): 6 Years of Follow-up
}

Jason M. Cuellar, Alexandre Rasouli, Todd H. Lanman, Lea Kanim and Rick Delamarter

Int J Spine Surg 2021, 15 (5) 971-977

doi: https://doi.org/10.14444/8127

http://ijssurgery.com/content/15/5/971

This information is current as of April 26, 2023.

Email Alerts Receive free email-alerts when new articles cite this article. Sign up at:

http://ijssurgery.com/alerts

The International Journal of Spine Surgery

2397 Waterbury Circle, Suite 1,

Aurora, IL 60504, Phone: +1-630-375-1432 


\title{
Single and Multilevel Lumbar Total Disc Replacement Adjacent to L5-S1 ALIF (Lumbar Hybrid): 6 Years of Follow-up
}

\author{
JASON M. CUELLAR, MD, PHD, ${ }^{1}$ ALEXANDRE RASOULI, MD,${ }^{1}$ TODD H. LANMAN, MD ${ }^{2}$ \\ LEA KANIM, MS, ${ }^{1}$ RICK DELAMARTER, $\mathrm{MD}^{1}$ \\ ${ }^{I}$ Department of Orthopaedic Surgery, Cedars-Sinai Medical Center, Los Angeles, California, ${ }^{2}$ Department of Neurosurgery, Cedars-Sinai Medical Center, \\ Los Angeles, California
}

\begin{abstract}
Background: Single and multilevel lumbar arthroplasty has had excellent results, but the L5-S1 level frequently has pathology that precludes arthroplasty. This study evaluated clinical outcomes and sagittal range of motion (ROM) of operated levels and adjacent motion segments in single- and multiple-level ProDisc-L above a simultaneous L5-S1 fusion (hybrid) after a 2- to 6-year follow-up.

Methods: In this prospective cohort study, 46 patients underwent simultaneous lumbar total disc replacement (TDR) at one to three levels and anterior lumbar interbody fusion (ALIF) at L5-S1. Twenty-three patients had L5-S1 ALIF + L4-5 TDR, 19 patients had L5-S1 ALIF + two-level TDR, and 4 patients had L5-S1 ALIF + three-level TDR. Oswestry disability index (ODI) and visual analog scores (VAS) of patient satisfaction (VAS-S) and pain (VAS-P) were recorded. Sagittal motion on pre- and postoperative lumbar radiographs at each operative segment and adjacent segment was acquired. Patients were evaluated preoperatively and at 6 weeks, 3 months, 6 months, and annually for 24 to 72 months postoperatively.

Results: For clinical results, there were no differences among the groups for age, gender, body mass index, tobacco use, or worker's compensation status. At 2-6 years postoperation, all patients had significant reductions in ODI and VAS scores. For radiographic results, at the nonsurgical level adjacent to the TDR + ALIF constructs, the mean preoperative $\mathrm{ROM}$ was $9.40 \pm 1.80^{\circ}$ compared with $10.50 \pm 2.25^{\circ}$ postoperatively. The mean preoperative ROM at levels undergoing TDR was $10.4 \pm 2.71^{\circ}$ versus $12.6 \pm 2.25^{\circ}$ postoperatively. There was no statistically significant difference in ROM at each prosthetic motion segment between patients receiving one-, two-, or three-level TDR. The mean preoperative ROM at the L5-S1 segment to undergo fusion was $2.4 \pm 2.44^{\circ}$, with all patients having a postoperative ROM of $0.00^{\circ}$.

Conclusions: Multilevel TDR above an L5-S1 ALIF (hybrid procedure) preserves ROM at the individual TDR levels and does not reduce the fusion rate of the L5-S1 fused level. Most significantly, the nonoperative adjacent level maintains its preoperative ROM at 2-6 years postoperatively.
\end{abstract}

Total Disc Replacement

Keywords: lumbar hybrid, multilevel lumbar disc replacement, total disc replacement, lumbar disc arthroplasty, spine, low back pain, lumbar

\section{INTRODUCTION}

Fusion has long been considered the surgical treatment of choice for intractable back pain associated with disc degeneration. The clinical success of arthrodesis is thought to depend upon eliminating the painful motion between spinal segments by achieving bony healing between adjacent vertebral bodies. Over the years, great effort has been directed toward developing and refining surgical techniques intended to achieve improved rates of solid fusion in the hopes of improving clinical outcomes.
Unfortunately, despite advances in surgical technique and implant design, fusion rates continue to be far from perfect. Pseudoarthrosis remains a significant contributor to reoperation and ultimately poor outcomes after attempted fusion surgery, with a large meta-analysis of 47 publications on lumbar arthrodesis reporting an overall pseudoarthrosis rate of $14 \%{ }^{1}$

Perhaps more importantly, adjacent level degeneration has been identified as a major source of long-term morbidity associated with fusion procedures, with a large percentage of patients developing 
symptoms even after fusions considered to be successful initially. ${ }^{2-5}$ Penta et al found $32 \%$ of patients had adjacent level degenerative changes on magnetic resonance imaging 10 years after anterior lumbar interbody fusion. ${ }^{3}$ Kumar et al identified disc space narrowing in $36 \%$ of patients and osteophyte formation in $43 \%$ of patients 30 years after one- or two-level lumbar arthrodesis. ${ }^{4}$ Similarly, Ghiselli et al recorded symptomatic adjacent level disease in $36 \%$ of patients at 10 -year followup. $^{5}$

Total disc replacement (TDR) has been introduced with the goal of treating painful disc degeneration while maintaining motion and, at the same time, reducing the incidence of fusion-related morbidities. Disc arthroplasty procedures, through maintenance of motion, are not subject to pseudoarthrosis. But perhaps the most significant potential advantage of these motion-preserving procedures is the decrease or elimination of adjacent level degeneration by decreasing the transmission of damaging stress to adjacent segments.

The radiographic and clinical success of disc arthroplasty has been well documented for one-level disc degeneration, with randomized controlled studies demonstrating superior results at 2-year ${ }^{6}$ and 5 -year ${ }^{7-9}$ follow-up. High success rates have been reported at greater than 10 years after disc arthroplasty. ${ }^{10}$ Biomechanical studies have indicated that disc replacement procedures not only maintain motion at operative levels but also do not seem to cause abnormal motion or stress at adjacent levels. ${ }^{11}$ A systematic review of the available literature by Harrop et al found a strong correlation between fusion and the development of adjacent segment degeneration when compared with disc arthroplasty. ${ }^{12}$ Zigler et al recently reported a significantly lower rate of adjacent segment degeneration at 5 years after disc arthroplasty than after fusion. ${ }^{8,13}$

Patients very commonly present with disc degeneration at multiple levels. Similar to one-level disc replacement, recent studies have reported encouraging results with multilevel disc arthroplasty procedures with 2 to 6 years follow-up. ${ }^{14-16}$

Unfortunately, a number of patients present with multilevel disc degeneration of varying severity. These patients are suitable candidates for disc arthroplasty at some levels but have either severe disc degeneration or other pathology that makes disc replacement contraindicated at other levels.
Bertagnoli et al has demonstrated disc arthroplasty to be efficacious for treating symptomatic disc degeneration above a previous fusion. ${ }^{14,17}$ Chen et al reported equal or better clinical outcomes following the lumbar hybrid construct than ALIF alone. ${ }^{18}$ Scott-Young et al have recently reported outcomes of a large series of patients undergoing a single-level artificial disc replacement and an anterior fusion procedure simultaneously at an adjacent level. ${ }^{19}$

The present study was designed to present the radiographic and clinical outcomes of a group of patients undergoing a "hybrid" procedure involving one, two, or three simultaneous lumbar artificial disc replacements above an arthrodesis at the L5-S1 level.

\section{METHODS}

Forty-six consecutive patients underwent lumbar TDR using ProDisc-L (Synthes Spine, Westchester, PA) at one or more levels simultaneously with anterior lumbar interbody fusion (ALIF) using an InFix (Abbott Spine, Austin, TX) stand-alone cage. All 46 patients had ALIF procedures at the L5-S1 level augmented with rhBMP-2 (InFuse, Medtronic Sofamor Danek, Memphis, TN). Twenty-three patients had one-level TDR at L4-5, 19 patients had two-level TDR at L3-4 and L4-5, and 4 patients had three-level TDR at L2-3, L3-4, and L4-5. Patients were evaluated clinically and radiographically at their initial preoperative visit as well as at 3 months, 6 months, 12 months, and annually postoperatively. Indication for surgery was low back pain with or without radiculopathic pain in the setting of disc herniation or significant disc degeneration. The L5-S1 level was fused if there was significant facet arthropathy, and thus arthroplasty was not indicated.

Oswestry disability index (ODI), visual analog score for pain (VAS-P), and visual analog score for satisfaction (VAS-S) data were also collected at each follow-up interval. Along with the surveys, patients were also asked whether they would choose to undergo the surgery again. Each visit also included an evaluation of nerve tension signs (straight-leg and femoral stretch test), sensation to light touch, lower extremity motor strength, and patellar and Achilles reflexes.

Radiographic examination included lateral flexion and extension films from which sagittal motion was measured at all operative levels as well as 
adjacent nonoperative levels. Segmental range of motion (ROM) was obtained by calculating the difference between segmental lordosis at flexion and extension using the "spike method" previously described. ${ }^{5}$ Measurements were performed using a precision digital goniometer with resolution of $0.1^{\circ}$ (Macklanburg-Duncan Electronic Digital Protractor, Oklahoma City, OK). Every film was analyzed independently by 3 experienced spine surgeons. Each radiograph was measured twice by the same observer, yielding 6 measurements per radiograph.

For statistical analysis, patients were grouped according to the number of adjacent prosthetic discs received: TDR-1, TDR-2, or TDR-3. Mean and standard deviation were calculated for numerical values derived from the ODI, VAS-P, and VAS-S. Statistical significance for differences between final postoperative and original preoperative values and for differences in outcomes between groups according to numbers of discs replaced were determined by analysis of variance.

Segmental ROM values at a given operative level (eg, L4-L5) within a group (eg, TDR-3) were averaged and compared with the mean preoperative ROM at that level. The mean postoperative segmental ROM at a given level in a given group was also compared with the ROM of that same level in the other groups (ROM of L4-L5 in TDR-1 versus that in TDR-2 versus TDR-3). Statistical significance for differences between pre- and postoperative ROM at a given level and between ROM of a given level across the various groups were obtained using the Student $t$ test. As for the ROM for the adjacent segment (not undergoing TDR), postoperative values in each grouping were averaged and compared with the mean preoperative ROM values. For all comparisons, $P$ values less than .05 were deemed significant.

\section{RESULTS}

At all levels undergoing TDR, the mean preoperative ROM was $10.4 \pm 2.4^{\circ}$. Following arthroplasty with ProDisc-L, the mean postoperative ROM was $12.6 \pm 1.1^{\circ}(P=.011)$. No significant difference was found in postoperative ROM at TDR levels when comparing patients undergoing one-, two-, or three-level TDR $(P>.05$ for all comparisons between groups). At the L5-S1 level, the mean preoperative ROM was $2.4 \pm 2.2^{\circ}$. Following ALIF with the InFix cage, the mean postoperative ROM at final follow-up (2-6 years)

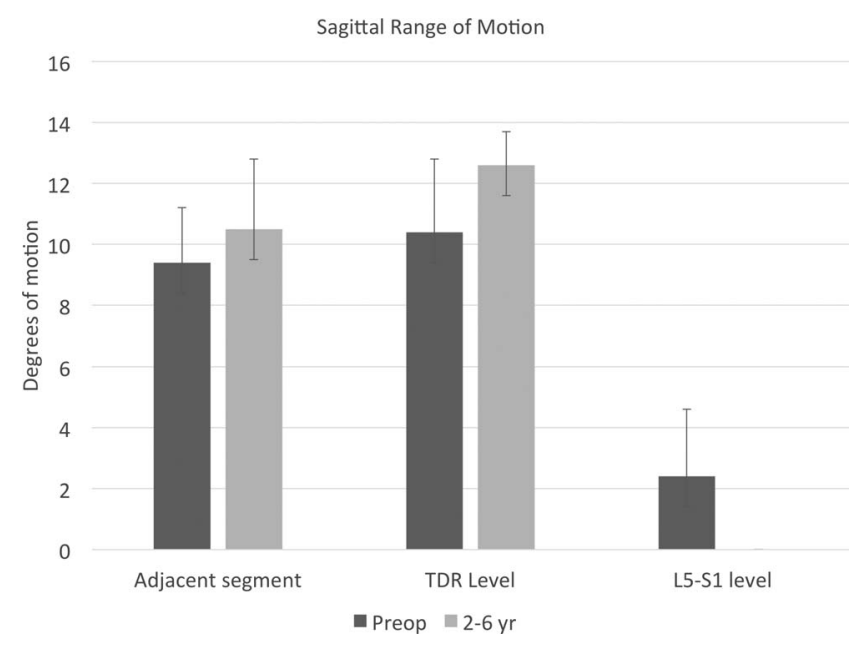

Figure 1. Radiographic motion (degrees) measured on the lateral view of flexion and extension radiographs preoperative and at last follow-up. Comparison between the L5-S1 fusion level, the total disc replacement, and adjacent level. Error bars are standard deviation. TDR, total disc replacement, one, two, or three signifies levels replaced above the L5-S1 fused level.

was $0.0^{\circ}(P>.05)$. All patients were clinically and radiographically determined to have solid fusion at L5-S1 at latest follow-up. At the level directly adjacent to TDR, the mean preoperative ROM was $9.4 \pm 1.8^{\circ}$. Following surgery at caudal levels, ROM at the adjacent level was $10.5 \pm 2.3^{\circ}(P=.21)$ (Figure 1).

There were no significant differences in the baseline preoperative ODI score according to number of levels to be operated: TDR-1 $=43.2$ points, TDR $-2=42.8$ points, TDR-3 $=39.4(P>$ .05). All groups exhibited statistically significant progressive improvement in ODI relative to preoperative levels. For the TDR-1 patients, there was an average $42.0 \%$ improvement at 6 weeks and $46.0 \%$ at 72 months. TDR-2 patients had an average improvement of $38.0 \%$ at 6 weeks and $40.0 \%$ at 24 months. For the TDR-3 patients, there was an average $18.0 \%$ improvement at 6 weeks and $38.6 \%$ at 24 months. These between-group differences did not achieve statistical significance $(P>.05$ for all three comparisons) (Figure 2).

There were no significant differences among the groups in preoperative VAS-P scores: 6.7 for TDR1, 8.0 for TDR-2, and 7.6 for TDR-3 $(P=.22)$. All groups showed improvement in reported pain relative to preoperative levels. TDR-1 values improved by an average of $51.0 \%$ at 6 weeks and $53.0 \%$ at 72 months (compared with preoperative values). TDR-2 values improved by an average of $43.0 \%$ at 6 weeks and $58.0 \%$ at 24 months. TDR-3 values improved by an average of $48 \%$ at 6 weeks 


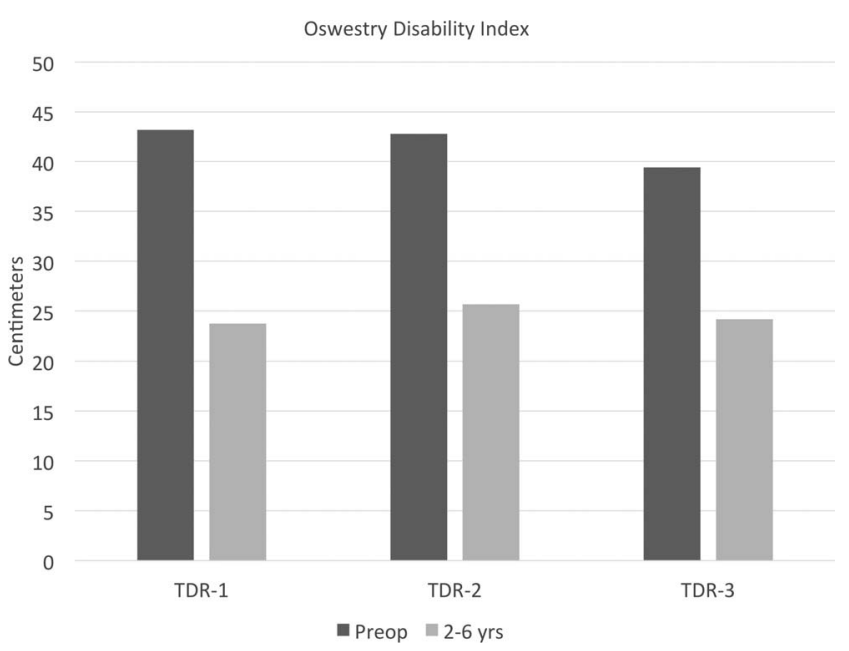

Figure 2. Average Oswestry disability index before surgery and at the latest follow-up period in patients receiving one-, two-, or three-level TDR above the L5-S1 fused level.

and $55.0 \%$ at 24 months. For each group, all differences between preoperative and postoperative scores were statistically significant $(P<.001)$. In group-to-group comparison, the differences in final improvement did not reach statistical significance $(P$ $>.50$ for each comparison) (Figure 3).

The average VAS-S scores ranged from $8.6 \mathrm{~cm}$ at 6 weeks to $8.4 \mathrm{~cm}$ at 72 months in the TDR-1 group, from $7.6 \mathrm{~cm}$ at 6 weeks to $7.5 \mathrm{~cm}$ at 24 months in the TDR-2 group, and from $8.30 \mathrm{~cm}$ at 6 weeks to 8.20 $\mathrm{cm}$ at 24 months in the TDR-3 group. The stated improvement in satisfaction at 24-72 months was similar across all three groups $(P>.50$ for differences between the groups). The differences between final endpoint and 6-week scores were statistically insignificant $(P>.05$ for all three

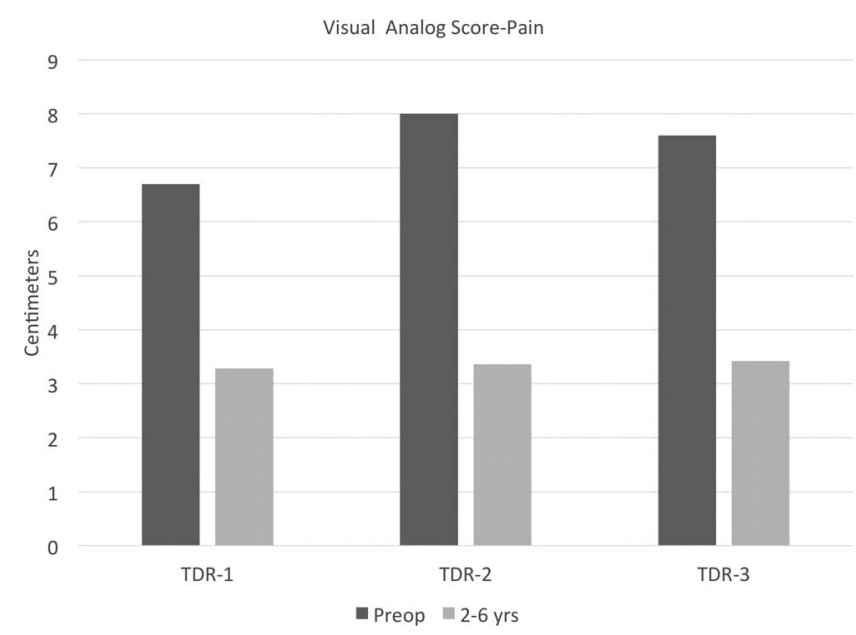

Figure 3. Visual analog pain score before surgery and at the latest follow-up period in patients receiving one-, two-, or three-level TDR above the L5-S1 fused level.

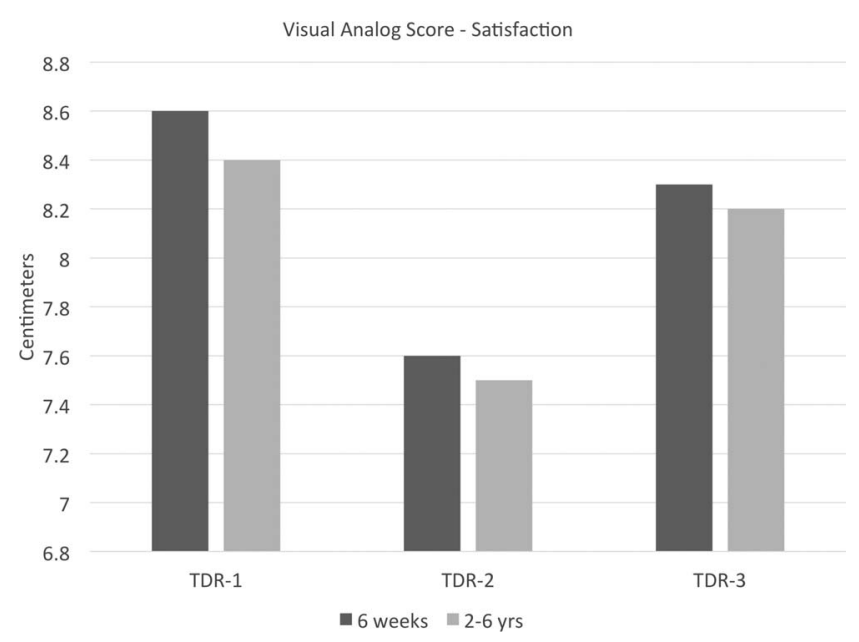

Figure 4. Visual analog satisfaction score before surgery and at the latest follow-up period in patients receiving one-, two-, or three-level TDR above the L5-S1 fused level.

comparisons) (Figure 4). All patients responded positively to the question "Would you undergo this surgery again?" at each time point at which it was asked. See Figures 5 and 6 for examples of preoperative magnetic resonance imaging and postoperative radiographs following two- and threelevel TDR above L5-S1 ALIF.

This cohort of patients did not experience any major postoperative complications, including deep venous thrombosis, pulmonary embolism, wound infections, or hematomas requiring reoperation or drainage. None of the patients required reoperation for any reason nor were any device failures identified during the follow-up period.

\section{DISCUSSION}

Previous literature has demonstrated lumbar TDR to be successful both radiographically, in terms of maintaining ROM at operative levels, and also clinically, with regard to pain relief and overall patient satisfaction. ${ }^{5}$ The majority of the published research to date has involved single-level TDR, but recent studies have shown similar favorable results with multilevel lumbar TDR. ${ }^{15-17}$

The "hybrid" construct, involving a combination of motion preserving disc arthroplasty adjacent to a traditional fusion, was initially described by Bertagnoli et al. ${ }^{14}$ Subsequently, Bertagnoli et $\mathrm{al}^{17}$ provided 2-year follow-up data on a group of patients who underwent artificial disc replacement for degenerative disc disease adjacent to a previous fusion. Scott-Young et al recently published a large series of 617 patients that underwent the lumbar 


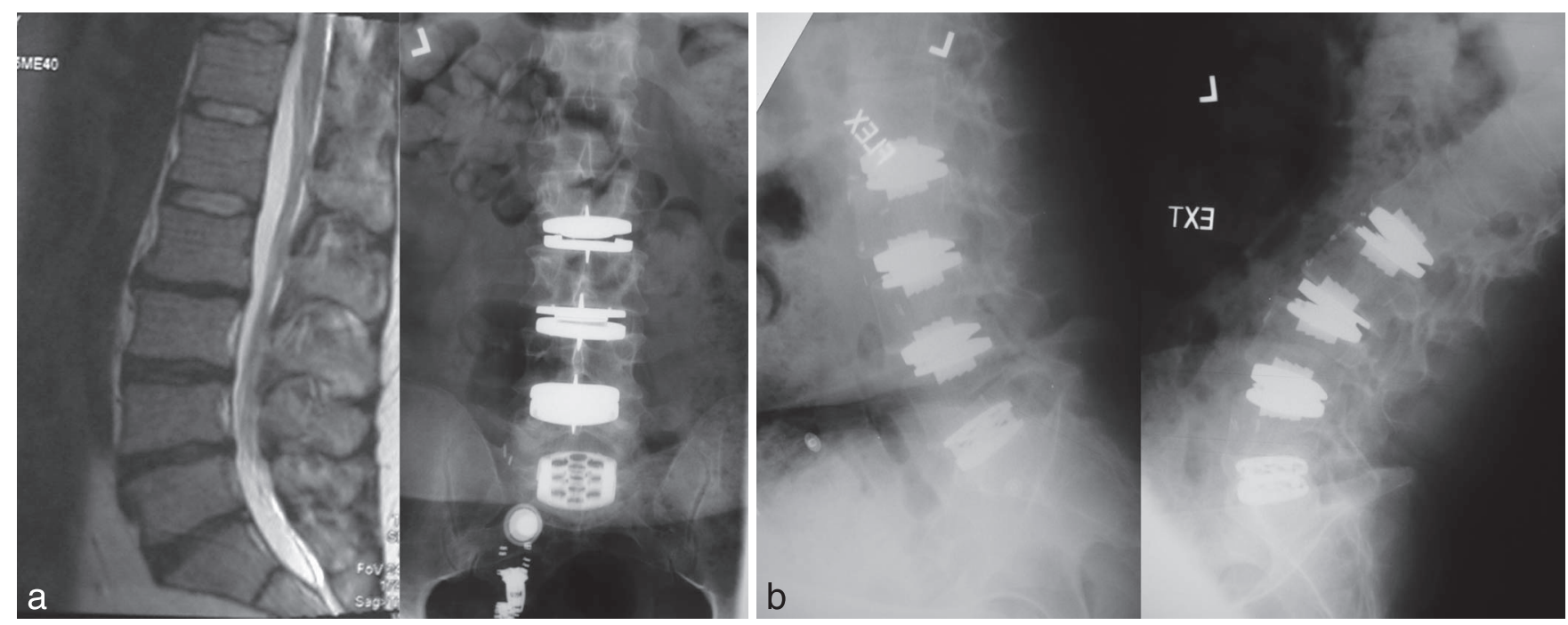

Figure 5. (a) Preoperative sagittal magnetic resonance image cut (left) and postoperative anterior-posterior radiograph (right) in a patient that underwent a threelevel total disc replacement above an L5-S1 anterior lumbar interbody fusion. (b) Postoperative flexion (left) and extension (right) lateral radiographs in the same patient as in panel a.

hybrid procedure at L4-5 and L5-S1. ${ }^{19}$ The authors observed long-term sustained pain relief at 8 years postoperation.

The purpose of this study was to present the radiographic and functional outcomes of a cohort of patients presenting with multilevel lumbar degenerative disc disease who underwent a hybrid procedure involving the simultaneous placement of TDR at multiple levels adjacent to an ALIF at L5S1.

There are several important findings associated with this group of patients. It has now been demonstrated in numerous studies that spinal segments adjacent to a fusion experience increased stress, leading to accelerated disc degeneration. ${ }^{2-5}$ One of the most important potential advantages of disc arthroplasty is the prevention of this abnormal stress and possible elimination of adjacent segment degeneration. A study by Huang et al has shown a clear relationship between motion of disc arthroplasty and the development of adjacent segment degeneration with over 8 years follow-up, ${ }^{20}$ and Zigler et al have reported lower rates 5 years after lumbar disc arthroplasty than after fusion. ${ }^{8}$ Patients with motion $5^{\circ}$ or greater at the level adjacent to disc arthroplasty showed $0 \%$ prevalence of degen-
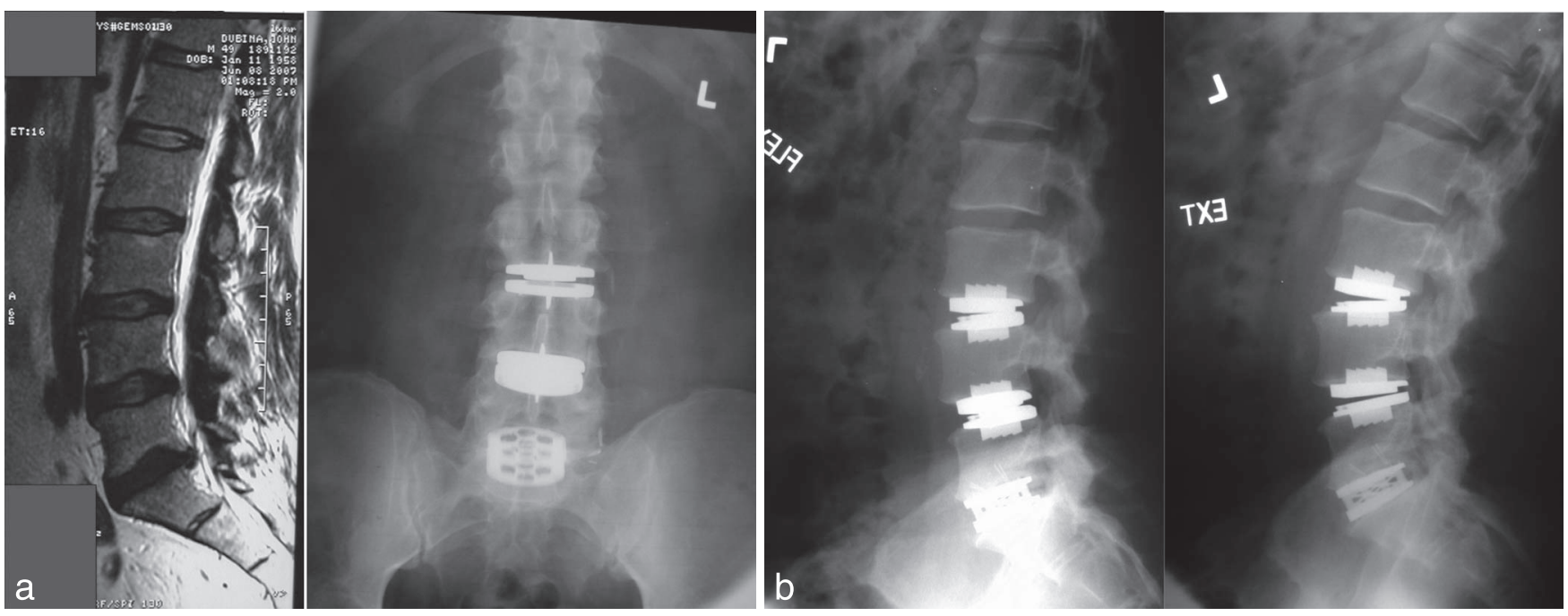

Figure 6. (a) Preoperative sagittal magnetic resonance image cut (left) and postoperative anterior-posterior radiograph (right) in a patient that underwent a two-level total disc replacement above an L5-S1 anterior lumbar interbody fusion. (b) Postoperative flexion (left) and extension (right) lateral radiographs in the same patient as in panel a. 
eration, while those with motion less than $5^{\circ}$ had a $34 \%$ prevalence of adjacent level disease. ${ }^{20}$ Our cohort of hybrid patients demonstrated a mean postoperative ROM at TDR levels of $12.6^{\circ}$, which should represent adequate motion to reduce the risk of adjacent segment degeneration. Similarly, our patients demonstrated a postoperative ROM of $10.5^{\circ}$ at adjacent levels compared with $9.4^{\circ}$ at the preoperative evaluation, indicating that a physiologic ROM was maintained after the hybrid procedure.

Another key finding of this study involves the successful rate of fusion at the L5-S1 spinal level within the hybrid construct. We obtained a solid fusion in all 46 patients, both clinically and radiographically. No pseudoarthroses were identified, and postoperative ROM at the L5-S1 level remained at $0.00^{\circ}$. This clearly demonstrates that the hybrid construct permits successful fusion at desired levels without interference from retained motion at adjacent level disc replacement. Conversely, all levels treated with disc replacement demonstrated excellent maintenance of ROM in the presence of simultaneous attempted fusion at L5-S1.

\section{CONCLUSION}

Lumbar artificial disc replacement can successfully be performed at multiple levels with an ALIF during the same procedure. Postoperative ROM at TDR levels within a hybrid construct was similar to that found with TDR used alone with excellent maintenance of physiologic motion. Combining disc arthroplasty with fusion at adjacent segments did not adversely impact the desired outcome at either TDR levels or fusion levels. Most importantly, the hybrid construct results in the preservation of normal motion at nonoperative adjacent levels, potentially decreasing the development of adjacent segment degeneration.

\section{REFERENCES}

1. Turner JA, Ersek M, Herron L, et al. Patient outcomes after lumbar spinal fusions. JAMA 1992;268(7):907-911.

2. Hilibrand AS, Robbins M. Adjacent segment degeneration and adjacent segment disease: the consequences of spinal fusion? Spine J 2004;4(6 Suppl):190S-194S.

3. Penta M, Sandhu A, Fraser RD. Magnetic resonance imaging assessment of disc degeneration 10 years after anterior lumbar interbody fusion. Spine (Phila Pa 1976) 1995;20(6):743747.

4. Kumar MN, Jacquot F, Hall H. Long-term follow-up of functional outcomes and radiographic changes at adjacent levels following lumbar spine fusion for degenerative disc disease. Eur Spine J 2001;10(4):309-313.

5. Ghiselli G, Wang JC, Bhatia NN, Hsu WK, Dawson EG. Adjacent segment degeneration in the lumbar spine. $J$ Bone Joint Surg Am 2004;86(7):1497-1503.

6. Zigler J, Delamarter R, Spivak JM, et al. Results of the prospective, randomized, multicenter Food and Drug Administration investigational device exemption study of the ProDisc$\mathrm{L}$ total disc replacement versus circumferential fusion for the treatment of 1-level degenerative disc disease. Spine (Phila Pa 1976) 2007;32(11):1155-1162; discussion 63.

7. Guyer RD, McAfee PC, Banco RJ, et al. Prospective, randomized, multicenter Food and Drug Administration investigational device exemption study of lumbar total disc replacement with the CHARITE artificial disc versus lumbar fusion: five-year follow-up. Spine J 2009;9(5):374-386.

8. Zigler JE, Blumenthal SL, Guyer RD, Ohnmeiss DD, Patel L. Progression of adjacent-level degeneration after lumbar total disc replacement: results of a post-hoc analysis of patients with available radiographs from a prospective study with 5-year follow-up. Spine (Phila Pa 1976) 2018;43(20):1395-1400.

9. Zigler JE, Delamarter RB. Five-year results of the prospective, randomized, multicenter, Food and Drug Administration investigational device exemption study of the ProDisc-L total disc replacement versus circumferential arthrodesis for the treatment of single-level degenerative disc disease. J Neurosurg Spine 2012;17(6):493-501.

10. Lu SB, Hai Y, Kong C, et al. An 11-year minimum follow-up of the Charite III lumbar disc replacement for the treatment of symptomatic degenerative disc disease. Eur Spine $J$ 2015;24(9):2056-2064.

11. Dmitriev AE, Gill NW, Kuklo TR, Rosner MK. Effect of multilevel lumbar disc arthroplasty on the operative- and adjacent-level kinematics and intradiscal pressures: an in vitro human cadaveric assessment. Spine J 2008;8(6):918-25.

12. Harrop JS, Youssef JA, Maltenfort M, et al. Lumbar adjacent segment degeneration and disease after arthrodesis and total disc arthroplasty. Spine (Phila Pa 1976) 2008;33(15):17011707.

13. Zigler JE, Glenn J, Delamarter RB. Five-year adjacentlevel degenerative changes in patients with single-level disease treated using lumbar total disc replacement with ProDisc-L versus circumferential fusion. J Neurosurg Spine 2012;17(6):504-511.

14. Bertagnoli R, Tropiano P, Zigler J, Karg A, Voigt S. Hybrid constructs. Orthop Clin North Am. 2005;36(3):379-388.

15. Hannibal M, Thomas DJ, Low J, Hsu KY, Zucherman J. ProDisc-L total disc replacement: a comparison of 1-level versus 2-level arthroplasty patients with a minimum 2-year follow-up. Spine (Phila Pa 1976) 2007;32(21):2322-2326.

16. Rasouli A, Cuellar JM, Kanim L, Delamarter R. Multiple-level lumbar total disk replacement: a prospective clinical and radiographic analysis of motion preservation at 24 72 months. Clin Spine Surg 2019;32(1):38-42. doi:10.1097/BSD. 0000000000000704

17. Bertagnoli R, Yue JJ, Fenk-Mayer A, Eerulkar J, Emerson JW. Treatment of symptomatic adjacent-segment degeneration after lumbar fusion with total disc arthroplasty by using the prodisc prosthesis: a prospective study with 2-year minimum follow up. J Neurosurg Spine 2006;4(2):91-97.

18. Chen B, Akpolat YT, Williams P, Bergey D, Cheng WK. Survivorship and clinical outcomes after multi-level anterior 
lumbar reconstruction with stand-alone anterior lumbar interbody fusion or hybrid construct. J Clin Neurosci 2016;28:7-11. doi: 10.1016/j.jocn.2015.10.033

19. Scott-Young M, McEntee L, Schram B, Rathbone E, Hing W, Nielson D. Concurrent use of lumbar total disc arthroplasty and anterior lumbar interbody fusion: the lumbar hybrid procedure for the treatment of multilevel symptomatic degenerative disc disease: a prospective study. Spine (Phila Pa 1976) 2018;43(2):E75-E81.

20. Huang RC, Tropiano P, Marnay T, Girardi FP, Lim MR, Cammisa FP Jr. Range of motion and adjacent level degeneration after lumbar total disc replacement. Spine $J$ 2006;6(3):242-247.

Disclosures and COI: Rick Delamarter previously received royalties related to ProDisc.
Corresponding Author: Jason M. Cuellar, MD, PhD, Cedars-Sinai Spine Center, 444 South San Vicente Blvd, Ste 901, Los Angeles, CA 90048; mailing address: $450 \mathrm{~N}$ Roxbury Drive, 3rd Floor, Beverly Hills, CA 90210. Phone: (310)-385-7766; Email: cuellarj@gmail.com.

Published 3 December 2021

This manuscript is generously published free of charge by ISASS, the International Society for the Advancement of Spine Surgery. Copyright (C) 2021 ISASS. To see more or order reprints or permissions, see http://ijssurgery.com. 